\title{
Article \\ Compact Broadband Antenna with Vicsek Fractal Slots for WLAN and WiMAX Applications
}

\author{
Omaima Benkhadda 1,*(D), Sarosh Ahmad 2,3,*D, Mohamed Saih ${ }^{1}$, Kebir Chaji ${ }^{1}$, Abdelati Reha ${ }^{4}$, \\ Adnan Ghaffar ${ }^{5}$ (D), Salahuddin Khan ${ }^{6}$, Mohammad Alibakhshikenari ${ }^{3, *(D)}$ and Ernesto Limiti ${ }^{7}$ (D)
}

check for

updates

Citation: Benkhadda, O.; Ahmad, S.; Saih, M.; Chaji, K.; Reha, A.; Ghaffar, A.; Khan, S.; Alibakhshikenari, M.; Limiti, E. Compact Broadband Antenna with Vicsek Fractal Slots for WLAN and WiMAX Applications. Appl. Sci. 2022, 12, 1142. https:// doi.org/10.3390/app12031142

Academic Editors: Fabio Cavaliere and Luca Potì

Received: 5 December 2021

Accepted: 18 January 2022

Published: 21 January 2022

Publisher's Note: MDPI stays neutral with regard to jurisdictional claims in published maps and institutional affiliations.

Copyright: (C) 2022 by the authors. Licensee MDPI, Basel, Switzerland. This article is an open access article distributed under the terms and conditions of the Creative Commons Attribution (CC BY) license (https:// creativecommons.org/licenses/by/ $4.0 /)$.
1 Laboratory of Automatic, Energy Conversion and Microelectronics (LACEM), Faculty of Sciences and Technology, Sultan Moulay Slimane University, Beni Mellal 23000, Morocco; m.saih@usms.ma (M.S.); kebir.chaji@gmail.com (K.C.)

2 Department of Electrical Engineering and Technology, Government College University Faisalabad (GCUF), Faisalabad 38000, Pakistan

3 Department of Signal Theory and Communications, Universidad Carlos III de Madrid, 28911 Leganés, Madrid, Spain

4 Laboratory of Innovation in Management and Engineering for the Enterprise (LIMIE), ISGA Marrakech, Marrakech 40000, Morocco; Abdelati.reha@isga.ma

5 Department of Electrical and Electronic Engineering, Auckland University of Technology, Auckland 1010, New Zealand; aghaffar@aut.ac.nz

6 Electrical Engineering Department, College of Engineering, King Saud University, Riyadh 11421, Saudi Arabia; khanheu@gmail.com

7 Electronic Engineering Department, University of Rome “Tor Vergata”, Via Del Politecnico 1, 00133 Rome, Italy; limiti@ing.uniroma2.it

* Correspondence: oabenkhadda@gmail.com (O.B.); saroshahmad@ieee.org (S.A.); mohammad.alibakhshikenari@uc3m.es (M.A.)

\begin{abstract}
This paper aims to design a compact broadband antenna for wireless local area network (WLAN) and worldwide interoperability for microwave access (WIMAX) applications. The suggested antenna consists of an octagonal radiator with Vicsek fractal slots and a partial ground plane, it is printed on FR-4 dielectric substrate, and its global dimension is $50 \times 50 \times 1.6 \mathrm{~mm}^{3}$. The antenna is designed and constructed using both CST MICROWAVE STUDIO ${ }^{\circledR}$ and CADFEKO electromagnetic solver, and in order to validate the acquired simulation results, the antenna is manufactured and tested using vector network analyzer E5071C. The measurement results show that the designed antenna attains a broadband bandwidth $\left(S_{11}<-10 \mathrm{~dB}\right)$ from 2.48 to $6.7 \mathrm{GHz}$ resonating at 3.6 and $5.3 \mathrm{GHz}$, respectively. The broadband bandwidth covers the two required bands: WiMAX at the frequencies 2.3/2.5/3.3/3.5/5/5.5 GHz and WLAN at the frequencies 3.6/2.4-2.5/4.9-5.9 GHz. In addition, the suggested antenna provides good gains of $2.78 \mathrm{dBi}$ and $5.32 \mathrm{dBi}$, omnidirectional measured radiation patterns in the E-plane and the H-plane and high efficiencies of $88.5 \%$ and $84.6 \%$ at the resonant frequencies. A close agreement of about $90 \%$ between simulation and measurement results is noticed.
\end{abstract}

Keywords: broadband; octagonal microstrip patch antenna; Vicsek fractal; WLAN; WiMAX

\section{Introduction}

With fast progress in wireless technology systems, there is a strong request for antennas with low profiles, compact dimensions, planar geometry and especially the ability to provide a large impedance bandwidth for WLAN and WiMAX applications in several bands, such as 2.4-2.5/3.6/4.9-5.9 GHz and 2.3/2.5/3.3/3.5/5/5.5 GHz, respectively [1-3]. Microstrip antennas are the best type of antennas that meet these requirements due to their low weight, easy miniaturization, portability, installation flexibility, good performance and low manufacturing costs $[4,5]$.

In the literature, various structures of microstrip antennas are suggested to shield WLAN and WiMAX applications. Most of these antennas are slotted patch antennas fed by 
a coplanar waveguide (CPW) technique, such as CPW-fed monopole antennas, or a fractal antenna approach. A monopole antenna with a slot and dual ring resonator in the ground plane was proposed in [6] to achieve a triple band at 2.5, 3.7 and 4.6 GHz for WLAN and WiMAX applications. According to [7], a CPW-fed hexagonal shaped patch antenna was designed to achieve three bands i.e., 0.4, 1.2 and $1.75 \mathrm{GHz}$. These bands were obtained by inserting H-tree fractal slots in the radiating elements. Similarly, in [8], a Hilbert fractal slot was inserted in an octagonal radiator to operate in WLAN and WiMAX applications, and it offered a dual band at 2.48 and $5.68 \mathrm{GHz}$ with a bandwidth of about 0.7 and $3.55 \mathrm{GHz}$, respectively. A novel CPW rectangular antenna with a cantor fractal slot was developed in [9]; it shielded two bands of about 1 and $1.7 \mathrm{GHz}$ at resonant frequencies 3 and $5.1 \mathrm{GHz}$. Likewise, in [10], a compact antenna for UWB notched applications was developed; it covered a bandwidth from 3.1 to $10.6 \mathrm{GHz}$, with a rejected band from 2.4 to $2.484 \mathrm{GHz}$, for WLAN applications.

On the other hand, the defected ground structure DGS approach can be applied. A monopole antenna consisting of a rectangular ring and a fork-shaped strip with a defected ground plane was developed in [11] to generate three bands for WLAN and WiMAX applications at 2.5, 3.5 and 5.5 GHz. Thereafter in [12], a rectangular radiator with defected ground structure was suggested, offering three resonant frequencies of $2.40,3.5$ and $5.8 \mathrm{GHz}$ which shield the WLAN and WiMAX bands.

References [13-15] additionally propose antennas for WLAN and WiMAX applications using an asymmetrical feed line. In ref. [13], a compact antenna consisting of three monopoles with different lengths and an asymmetrical feed line was suggested to achieve four bands of about $0.17,0.16,0.17$ and $0.15 \mathrm{GHz}$ for WLAN and WiMAX applications. Naik, in [14], developed an asymmetric CPW antenna with a split ring for two bands for WLAN and WiMAX at 2.46 and $3.51 \mathrm{GHz}$ with bandwidths of about 0.17 and $0.15 \mathrm{GHz}$, respectively. An inverted L- shaped strip in the radiator, fed by an asymmetric CPW, was proposed in [15]; it offered a wide bandwidth of about $3.3 \mathrm{GHz}$ which covers the WLAN and WiMAX bands at 5.725-5.85 GHz and 3.3-3.7 GHz, respectively.

Furthermore, antennas for WLAN and WiMAX applications based on the metamaterial approach are presented in references [16-18]. In ref. [16], a compact antenna consisted of a utilizing complementary split ring resonators (CSRRs) placed in the radiator to reject four bands for WLAN and WiMAX applications at 3.4, 4.1, 4.8 and 5.6 GHz. Ken proposed, in [17], a broadband antenna composed of two interspaced ring resonators as radiator elements printed on FR-4 substrate, and the overall size of the antenna was $60 \times 90 \times 1.6 \mathrm{~mm}^{3}$. The antenna offered two bands of about 0.7 and $1.3 \mathrm{GHz}$ at 2.4 and $5.8 \mathrm{GHz}$. A CPW-fed metamaterial antenna was proposed in [18] to support WLAN and WiMAX applications at 2.4/5.5 GHz and 3.5 GHz bands, respectively.

The authors in [19] developed a MIMO antenna comprised of two spider-shaped radiators printed on FR-4 substrate sized $50 \times 37 \mathrm{~mm}^{2}$ to shield WLAN and WiMAX bands at 2.43, 3.83, 4.4 and 5.8 GHz. According to [20], a $4 \times 4$ MIMO antenna with dual operating bands was modelled, with four elements positioned on both sides of the dielectric material in the proposed MIMO antenna. Each element had a rectangular open-loop resonator inserted into the ground plane. The antenna had bandwidths of $0.08 \mathrm{GHz}$ and $0.17 \mathrm{GHz}$ at 2.46 and 3.5, respectively. WLAN (2.4-2.485 GHz) and WiMAX (3.4-3.6 GHz) bandwidth requirements were met.

The design in [21] was composed of two layers, one layer comprising an E-shaped patch and the second comprising a U-slot. The proposed antenna covered the WLAN at 2.4 GHz and the WiMAX at 3.5 GHz. Altaf, in [22], designed a Y-shaped dielectric resonator antenna with size of $120 \times 70 \mathrm{~mm}^{2}$; it presented two bands from $2.401 \mathrm{GHz}$ to $2.495 \mathrm{GHz}$ and from 3.4 GHz to $3.69 \mathrm{GHz}$ which shielded WLAN and WiMAX bands, respectively.

In all the above analyses, it can be observed that these antennas had complex structures with large areas, or they do not cover all the bands of WLAN and WiMAX applications. This work is related to the design of a broadband octagonal microstrip patch antenna with Vicsek fractal slots for WLAN and WiMAX applications. The investigated antenna offers a 
broadband of $4.22 \mathrm{GHz}$ from $2.48 \mathrm{GHz}$ to $6.7 \mathrm{GHz}$ with two resonant frequencies at $3.6 \mathrm{GHz}$ and $5.3 \mathrm{GHz}$ which shield both the WLAN and WiMAX bands.

The broadband characteristic is realized by using the fractal slots and partial ground plane. The designed antenna has good gains of $2.78 \mathrm{dBi}$ and $5.32 \mathrm{dBi}$, an omnidirectional radiation pattern in both the E-plane and the $\mathrm{H}$-plane and high efficiency of $88.5 \%$ and $84.6 \%$ at the resonant frequencies. In the first section of this paper, the antenna geometry and the design evolution procedure are described. A parametric analysis of critical dimensions is presented in Section 2. The discussion of the simulated and experimental results is elaborated upon in Section 3. The conclusion of this work is given in the last section.

\section{Antenna Geometry Design}

\subsection{Antenna Geometry}

The configuration of the suggested antenna is displayed in Figure 1. It comprises an octagonal radiator loaded with the two first iterations of Vicsek fractal slot structure, and it is engraved on a 1.6-mm-thick FR-4 dielectric substrate with relative permittivity $\varepsilon_{\mathrm{r}}=4.4$ and $\tan (\delta)=0.02$. In addition, a partial ground plane with initial dimensions $50 \times 15 \mathrm{~mm}^{2}$ is printed on the bottom side of the substrate. The antenna geometry has a complete size of $50 \times 50 \times 1.6 \mathrm{~mm}^{3}$ and a $50-\Omega$ feed line of width ' $W_{f}$ ' and length ' $L_{f}$ ' with an inset of length ' $d$ ', and gap ' $g$ ' is used to excite the antenna. The antenna has been designed and performed using the CST MWS simulator, and the optimal dimensions of the investigated antenna are listed in Table 1.

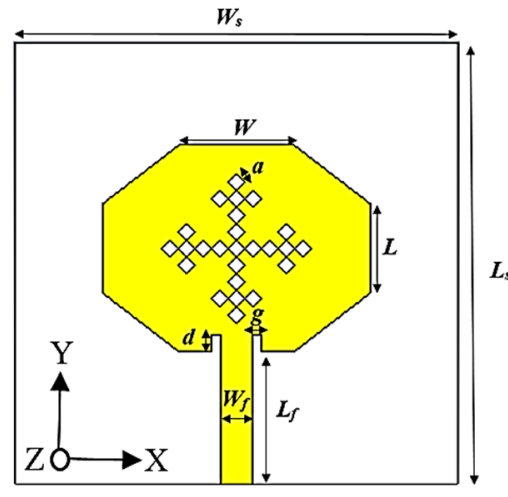

(a)

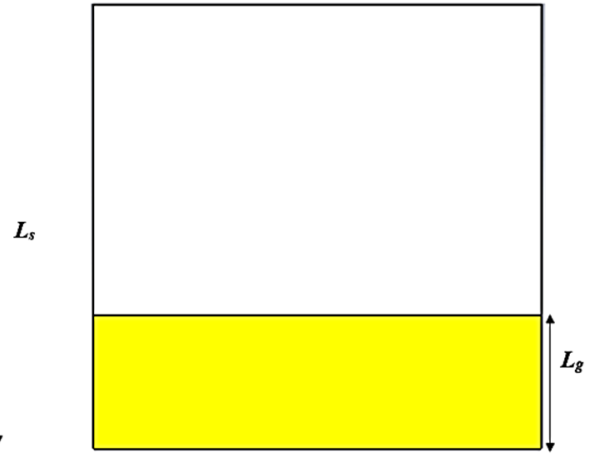

(b)

Figure 1. The suggested antenna structure with notations: (a) top view and (b) back view.

Table 1. Dimensions of the suggested antenna.

\begin{tabular}{cccc}
\hline Parameters & $\begin{array}{c}\text { Dimensions } \\
(\mathbf{m m})\end{array}$ & Parameters & $\begin{array}{c}\text { Dimensions } \\
(\mathbf{m m})\end{array}$ \\
\hline$W_{s}$ & 50 & $W$ & 13 \\
\hline$L_{s}$ & 50 & $L$ & 10 \\
\hline$W_{f}$ & 3.5 & $g$ & 1.3 \\
\hline$L_{f}$ & 15 & $g$ & 2 \\
\hline$L_{g}$ & 15 & $d$ & 1 \\
\hline
\end{tabular}

\subsection{Design Evolution Procedure}

Figure 2 presents the evolutionary stages of the investigated antenna. The antenna evolution process starts with a rectangular microstrip antenna excited by a feed line. Thereafter, four triangular parts are cut in the four angles of the rectangular radiator in order to make an octagonal radiator. Subsequently, the octagonal patch is loaded with the first and the second iterations of Vicsek fractal slots to achieve the final geometry. 


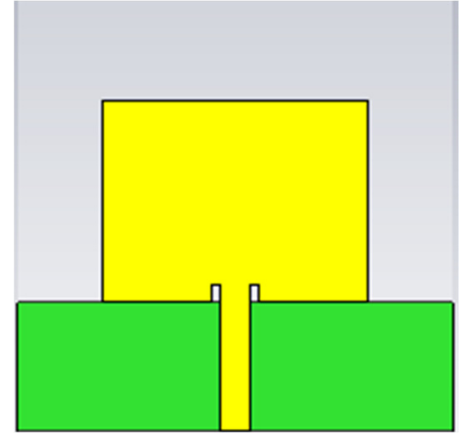

(a)

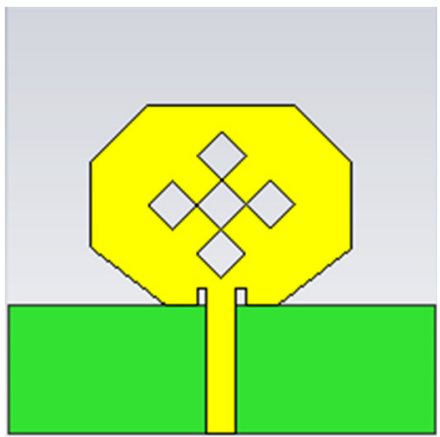

(c)

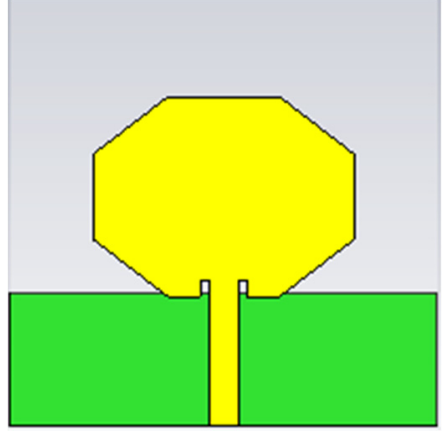

(b)

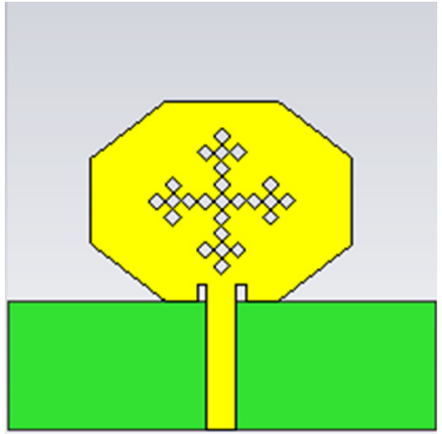

(d)

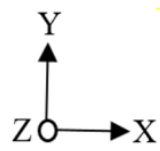

Figure 2. Evolution process of the suggested antenna: (a) simple microstrip patch (STEP I), (b) truncated patch (STEP II), (c) slotted patch (STEP III), (d) suggested patch (STEP IV).

The first step in the design of the suggested antenna is displayed in Figure 2a. A rectangular microstrip antenna of length $L_{p}$ and width $W_{p}$ was taken as a reference antenna (simple microstrip patch). The dimensions of the rectangular radiator were determined using the theory of transmission lines using the following Equations (1)-(4) [23]:

The width of a microstrip antenna can be calculated by:

$$
W=\frac{c}{2 f_{r}} \sqrt{\frac{2}{\varepsilon_{r}+1}}
$$

where $c$ and $\varepsilon_{r}$ are the speed of light $\left(3 \times 10^{8} \mathrm{~m} / \mathrm{s}\right)$ and relative permittivity of the medium, respectively, and $f_{r}$ represents the resonant frequency at which the antenna is designed. The effective dielectric constant of the substrate is yielded by [23]:

$$
\varepsilon_{r e f f}=\frac{\varepsilon_{r}+1}{2}+\frac{\varepsilon_{r}-1}{2} \times\left[1+12 \frac{h}{W}\right]^{-\frac{1}{2}}
$$

where $h$ is the substrate thickness. Finally, the length of the rectangular radiator is given by [24]:

$$
L=\frac{c}{2 f_{r} \sqrt{\varepsilon_{e f f}}}-2 \Delta L
$$

In Equation (3), $\Delta L$ corresponds to the increase in length of the antenna due to fringing effects and is given by [23]:

$$
\Delta L=0.412 \times h \times \frac{\left(\varepsilon_{r e f f}+0.3\right)+\left(\frac{W}{h}+0.264\right)}{\left(\varepsilon_{r e f f}-0.258\right)+\left(\frac{W}{h}+0.8\right)}
$$

The corresponding simulated $S_{11}$ of the different steps of the design process of the investigated antenna is depicted in Figure 3. The simple microstrip patch antenna generates 
one resonant frequency at $7.4 \mathrm{GHz}$, and it provides a bandwidth of $1.5 \mathrm{GHz}$. The truncated patch antenna structure is obtained by cutting four triangular shapes in the four angles of the radiating element to obtain an octagonal patch antenna as depicted in Figure $2 \mathrm{~b}$. It is noticed from Figure 4 that the truncated patch antenna provides a broadband of $3.91 \mathrm{GHz}$ from 2.29 to $6.2 \mathrm{GHz}$ with one resonant frequency at $3.8 \mathrm{GHz}$.

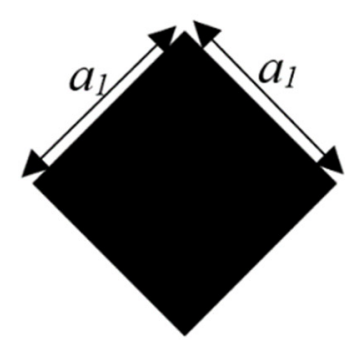

Iteration 0

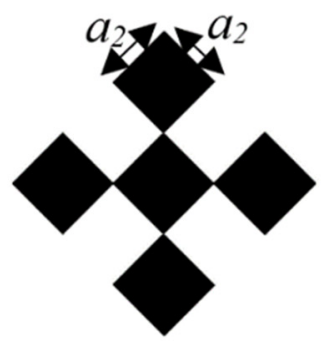

Iteration 1

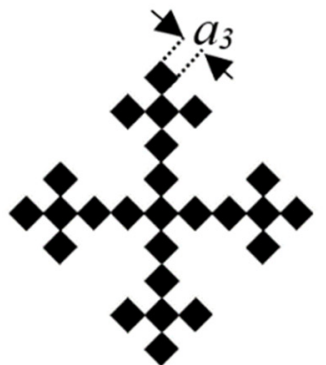

Iteration 2

Figure 3. The iterations of the Vicsek fractal structure.

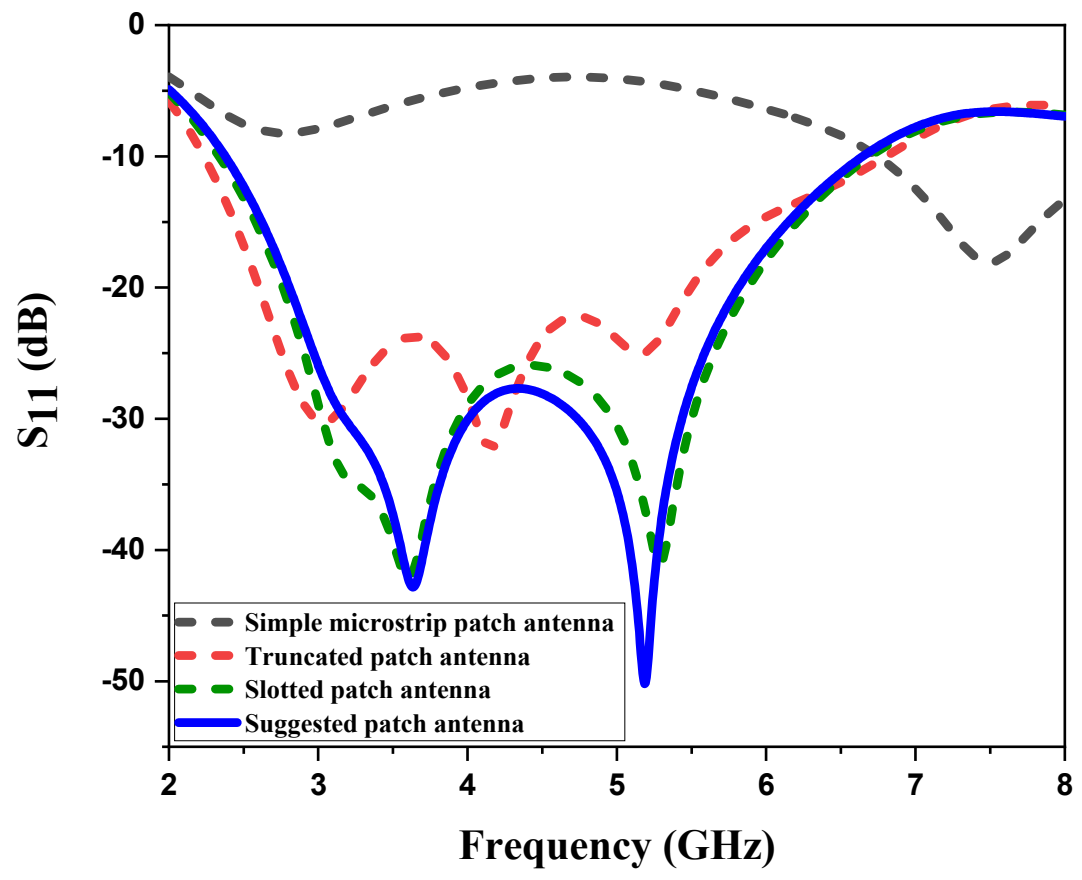

Figure 4. Simulated $S_{11}$ of the different evolutionary stages of the suggested antenna.

In the third step, the first iteration of Vicsek fractal slots is incorporated in the radiating element (slotted patch) as presented in Figure 2c.

The construction of Vicsek fractal slots is based on square rotated by $\pi / 4$ and decomposed into nine squares. The four corner squares and the middle square are kept, while the remaining squares are eliminated, as illustrated in the Vicsek fractal [24] with:

$$
a_{i}=\frac{a_{i-1}}{3}
$$

The Hausdorff dimension of the Vicsek fractal is presented by Equation (5) [24]:

$$
d=\frac{\ln (n)}{\ln (R)}=\frac{\ln (5)}{\ln (3)}=1.46496
$$

The slotted patch antenna presents a broadband of $4.3 \mathrm{GHz}$ from 2.3 to $6.6 \mathrm{GHz}$ with two resonant frequencies at 3.55 and $5.3 \mathrm{GHz}$ with reflection coefficients $-42 \mathrm{~dB}$ 
and $-40 \mathrm{~dB}$, respectively. Finally, the geometry of the suggested antenna is obtained by introducing the second iteration of Vicsek fractal slots on the octagonal patch antenna, as shown in Figure 2d. The suggested antenna achieves a broadband of $4.35 \mathrm{GHz}$ from 2.3 to 6.65 GHz with good impedance matching at resonant frequencies 3.6 and $5.2 \mathrm{GHz}$.

\subsection{Parametric Analysis of the Suggested Antenna}

The broadband characteristics of the suggested antenna are achieved with the help of parametric study. This study is used to obtain the optimal values of the antenna dimensions and the best performance by modifying one parameter and fixing the other parameters.

\subsubsection{The Feed Line Length $L_{f}$ and Width $W_{f}$ Variation Effects}

The effect of the microstrip feed line length $L_{f}$ on the suggested antenna performance is studied by changing the $L_{f}$ from 13 to $15 \mathrm{~mm}$ and the feed line width from $2.6 \mathrm{~mm}$ to $3.5 \mathrm{~mm}$. Figure 5 illustrates the variation of $S_{11}$ versus frequency for various lengths and widths of the feed line, $L_{f}$ and $W_{f}$. It can be noticed from the figure that by increasing the length of the feed line, the bandwidth increases from $3.8 \mathrm{GHz}$ to $4.35 \mathrm{GHz}$. The simulations confirm that to obtain good impedance matching and the desired broadband, the optimal values for the length and width of the feed line are $L_{f}=15 \mathrm{~mm}$ and $W_{f}=3.5 \mathrm{~mm}$.

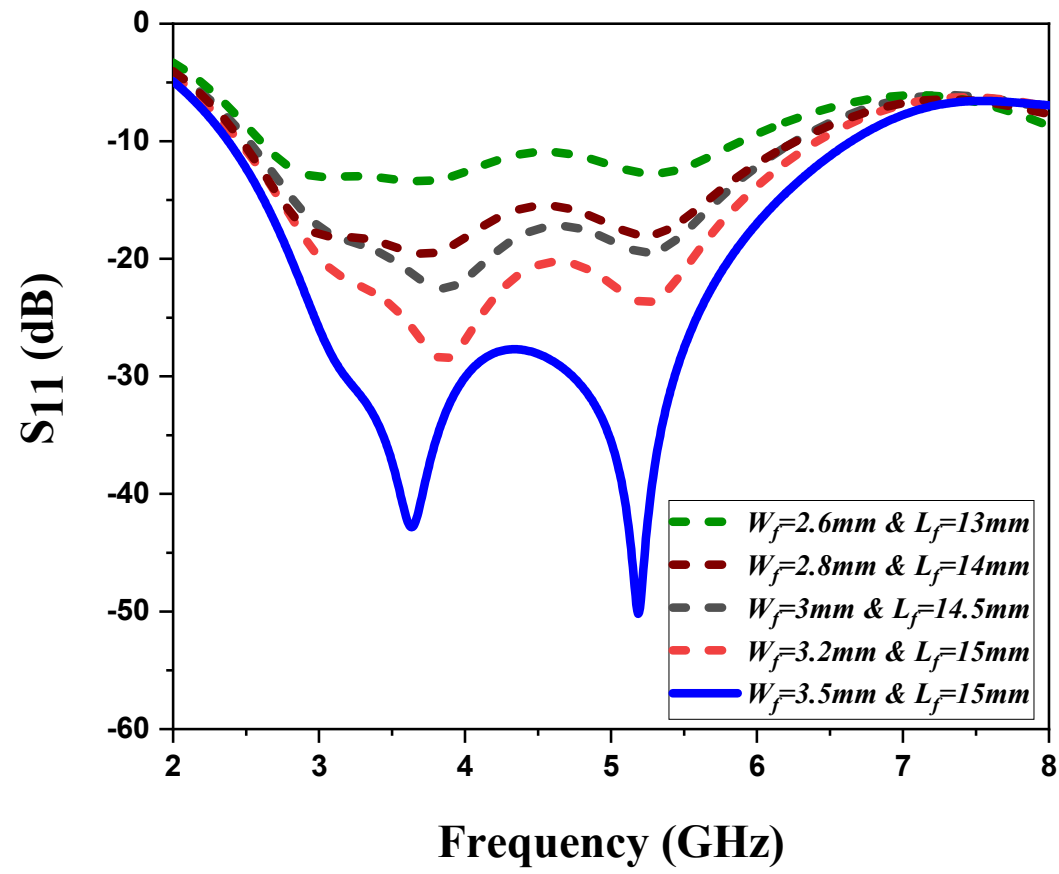

Figure 5. Parametric studies for the variation in the feed line length $L_{f}$ and width $W_{f}$.

\subsubsection{The Ground Plane Length $L_{g}$ Variation Effects}

Similar to $L_{f}$ and $W_{f}, L_{g}$ is also varied, as depicted in Figure 6. By changing the length $L_{g}$ from 13 to $16 \mathrm{~mm}$, the bandwidth increases from $1.5 \mathrm{GHz}$ to $4.35 \mathrm{GHz}$. Moreover, it is seen that the optimal value of the length of the ground plane is $L_{g}=15 \mathrm{~mm}$, for which the suggested antenna achieves the desired broadband with good impedance matching. 


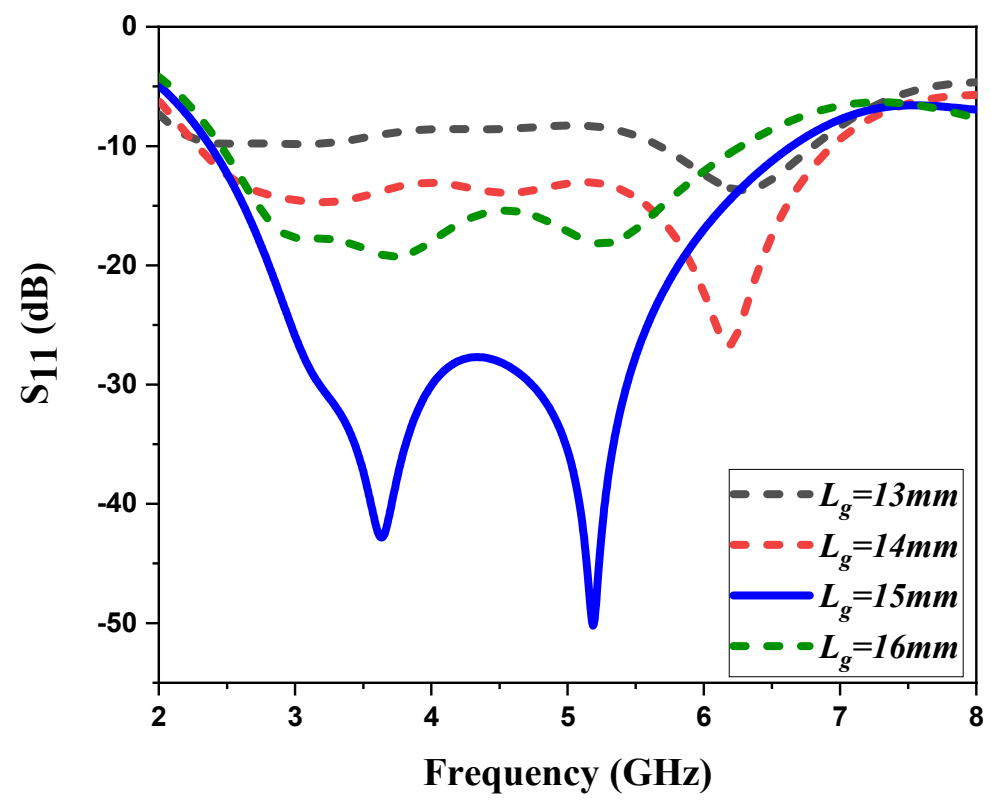

Figure 6. Parametric studies for the variation in the ground plane length $L_{g}$.

\subsubsection{The Vicsek Slot Length Variation Effects}

The parametric study in this section looks into the effect of the length of the Vicsek fractal slot on the impedance bandwidth and on the resonant frequencies. Figure 7 depicts the variation of $S_{11}$ when the length $a$ of the Vicsek fractal slot is changed and all other dimensions remain constant. It can be claimed from the figure that the parameter $a$ has no effect on the suggested antenna's impedance bandwidth but it does change the position of the resonant frequencies. The range of this parameter $(a)$ is between 0.7 and $1.6 \mathrm{~mm}$. Additionally, the value $a=1.3 \mathrm{~mm}$ is found to provide satisfactory impedance matching in the 3.6 and $5.8 \mathrm{GHz}$ frequencies corresponding to the WLAN and WiMAX bands.

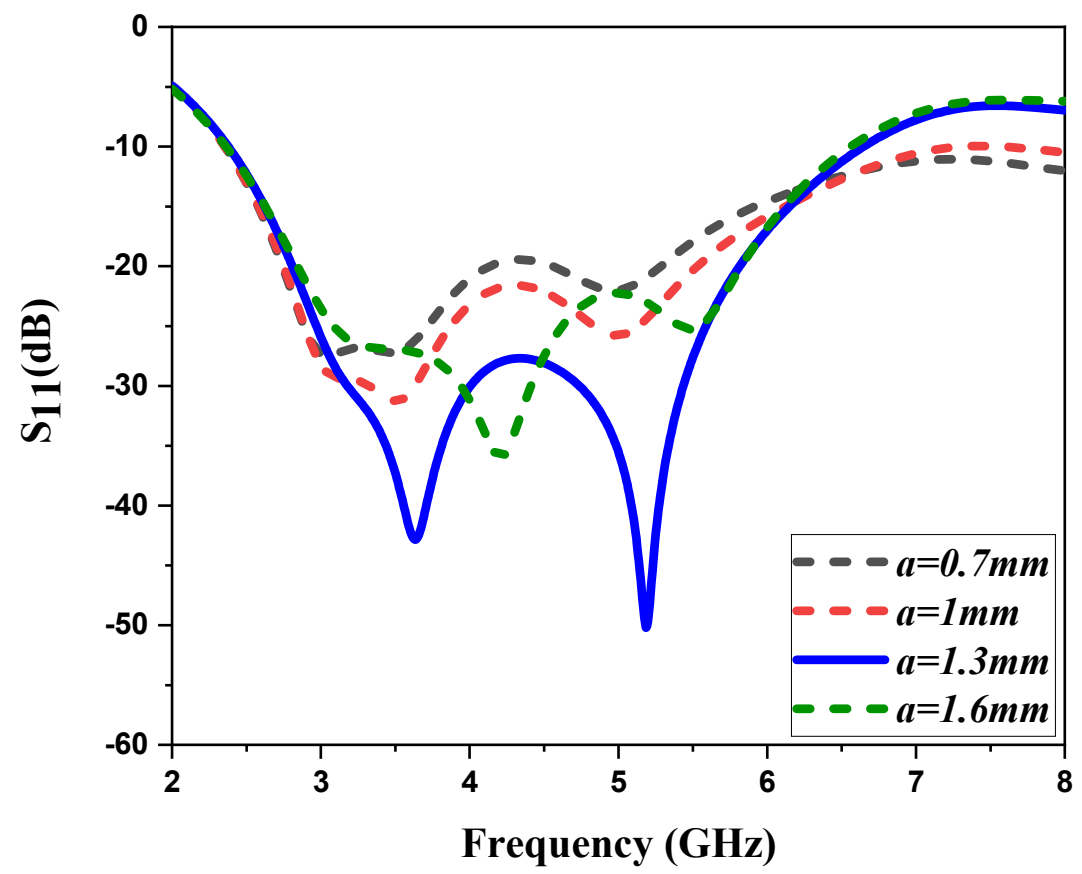

Figure 7. Parametric studies for the variation in the Vicsek fractal slot length $a$.

\section{Results and Discussion}

The simulation of the suggested antenna was carried out in both CST MICROWAVE STUDIO $^{\circledR}$, which is based on finite integration technology (FIT), and the CADFEKO 
simulator, which uses the method of moments (MoM). The antenna was excited by a waveguide port, and the boundary box had an area of $200 \mathrm{~mm} \times 200 \mathrm{~mm} \times 200 \mathrm{~mm}$, as shown in Figure 8, while the number of mesh cells was 374,088. To prove that the simulation results are accurate, the suggested broadband antenna was manufactured as depicted in Figure 9. The reflection coefficient $S_{11}$ was measured using vector network analyzer E5071C. The variation of the reflection coefficient $S_{11}$ of the suggested broadband antenna is illustrated in Figure 10. It is noticed from the measured results that the antenna presents a broadband of $4.22 \mathrm{GHz}$ from $2.48 \mathrm{GHz}$ to $6.7 \mathrm{GHz}$ with two resonant frequencies at 3.6 and $5.3 \mathrm{GHz}$ with reflection coefficients $-41.3 \mathrm{~dB}$ and $-57.2 \mathrm{~dB}$, respectively. The designed antenna provides a broadband which covers the WiMAX bands at frequencies 2.3/2.5/3.3/3.5/5/5.5 GHz and the WLAN at frequencies 3.6/2.4-2.5/4.9-5.9 GHz.

The simulated surface current distribution of the suggested broadband antenna results acquired by CST MICROWAVE STUDIO ${ }^{\circledR}$ at resonant frequencies 3.6 and $5.3 \mathrm{GHz}$ is depicted in Figure 11. It is seen from the figure that the current distribution is concentrated at the inset microstrip feed line, the ground plane and the extremity of the octagonal radiator at $3.6 \mathrm{GHz}$. Similarly, in the 5.3 GHz frequency, the high current surface is concentrated at the inset feed line, the ground plane.

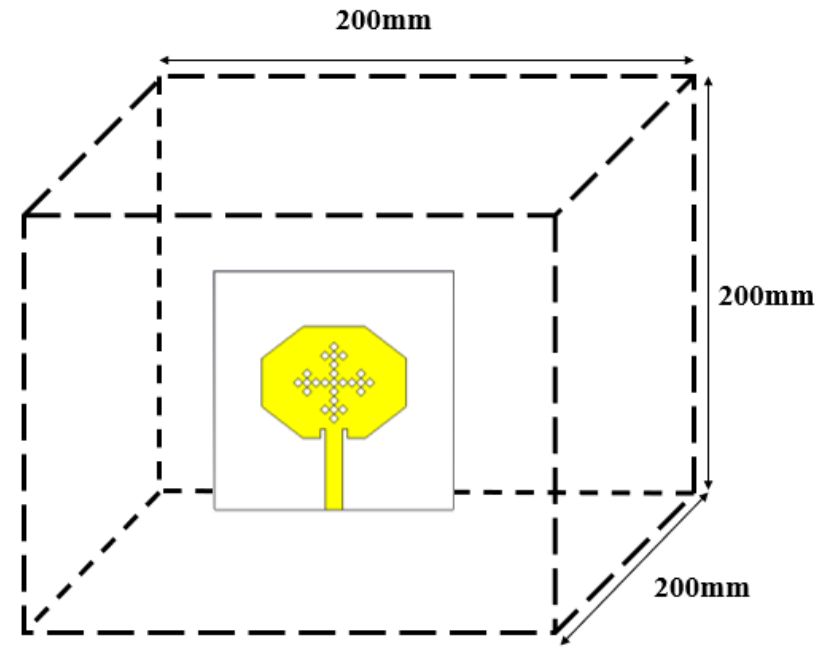

Figure 8. Boundary box of the proposed antenna.
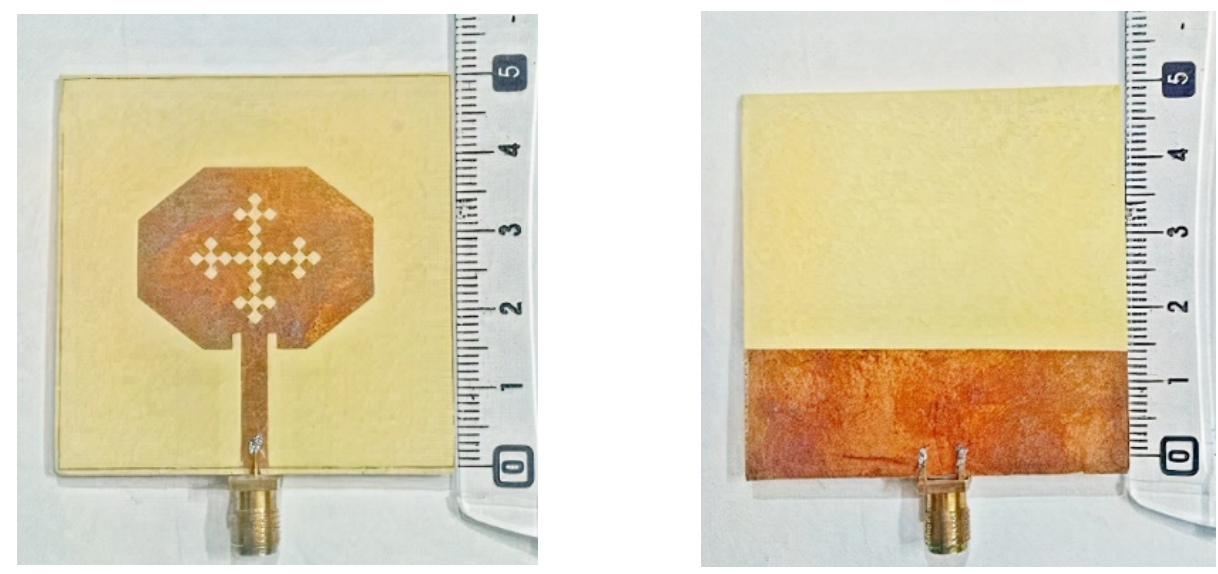

Figure 9. Manufactured prototype of the proposed antenna. 


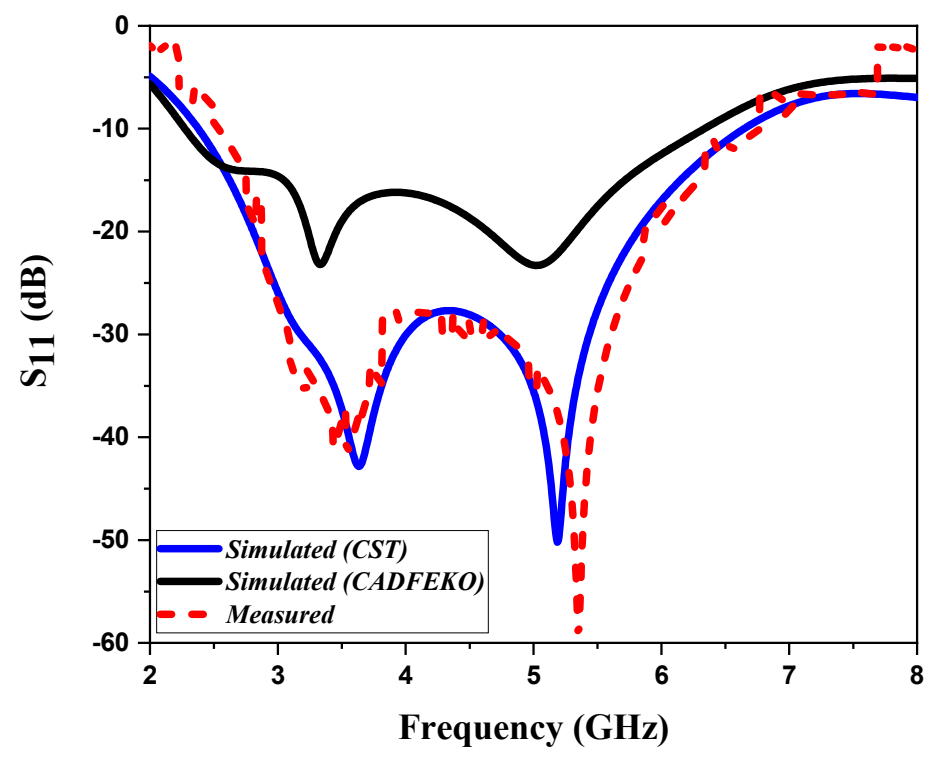

Figure 10. Measured and simulated S-parameters of the suggested antenna.

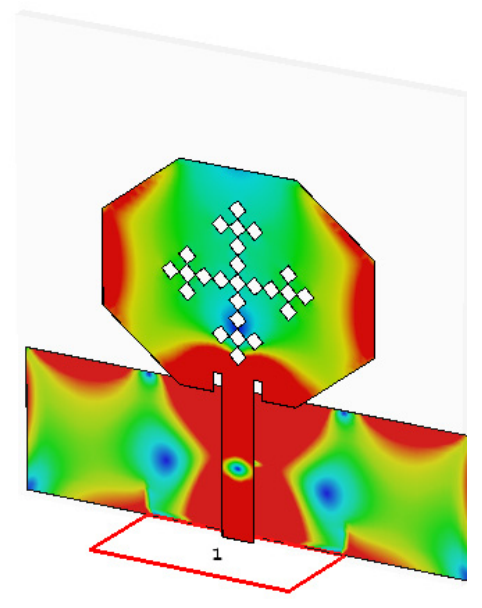

(a)

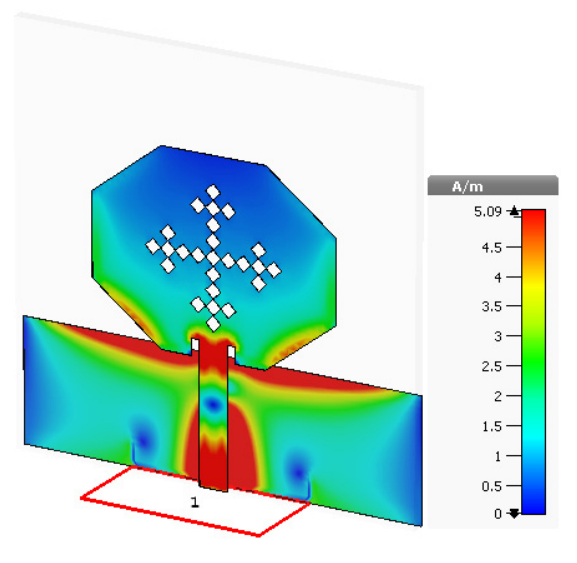

(b)

Figure 11. The simulated surface current distribution of the suggested broadband antenna at (a) 3.6 and (b) $5.3 \mathrm{GHz}$.

The measurements of radiation pattern and peak gain of the proposed antenna were made in an anechoic chamber, as shown in Figure 12. In addition, Figure 13 illustrates the measured radiation pattern together with the simulated results acquired by CST MICROWAVE STUDIO ${ }^{\circledR}$ and the CADFEKO simulator at resonant frequencies 3.6 and $5.3 \mathrm{GHz}$. It can be claimed from the figure that the suggested antenna presents a good radiation pattern performance since it achieves an omnidirectional pattern in the H-plane and in the E-plane.

The measured peak gain and simulated peak gain obtained by CST MICROWAVE STUDIO $^{\circledR}$ and CADFEKO software are illustrated in Figure 14 and the simulated radiation efficiency acquired by CST MWS is depicted in Figure 15. From the figures, it can be revealed that the suggested antenna presents good performance in terms of peak gain and radiation efficiency. The antenna offers considerable gains and radiation efficiencies: $2.78 / 5.32 \mathrm{dBi}$ and $88.5 / 84.6 \%$ at the operating frequencies $3.6 / 5.3 \mathrm{GHz}$, respectively. 


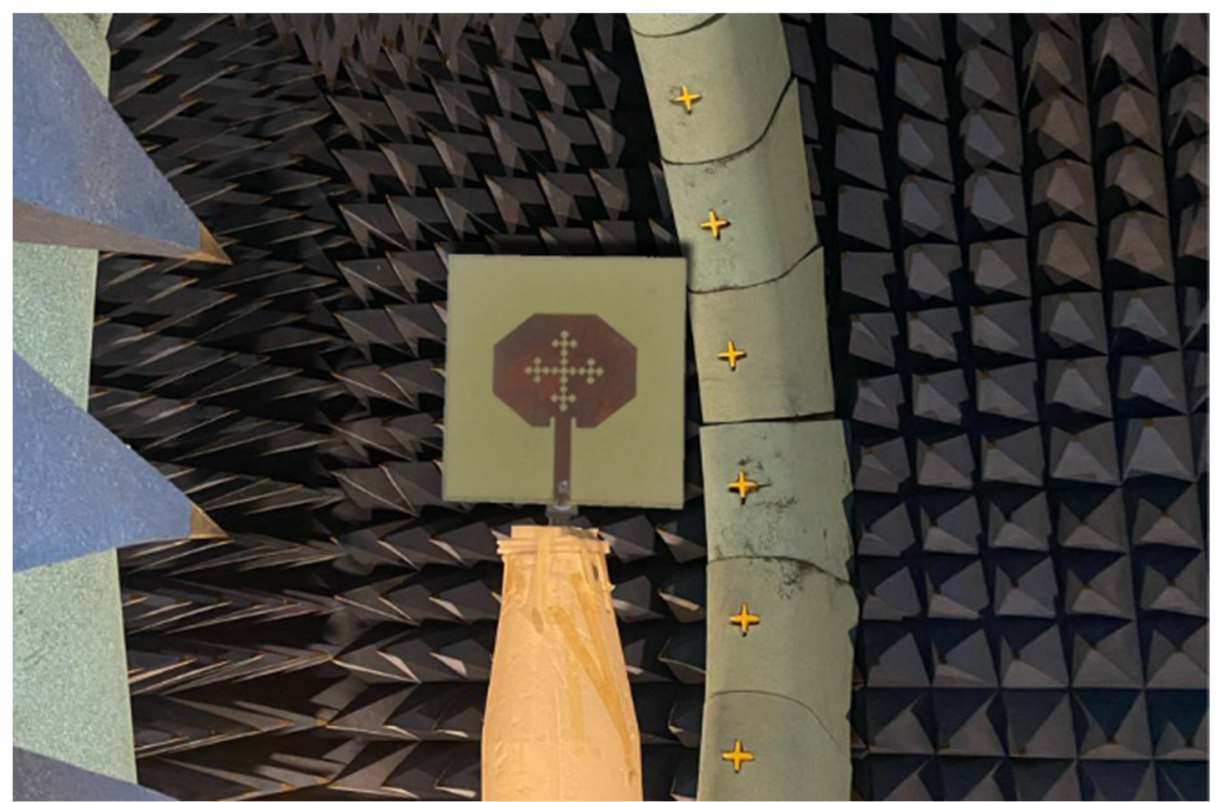

Figure 12. The measurement setup of radiation pattern and gain in an anechoic chamber.

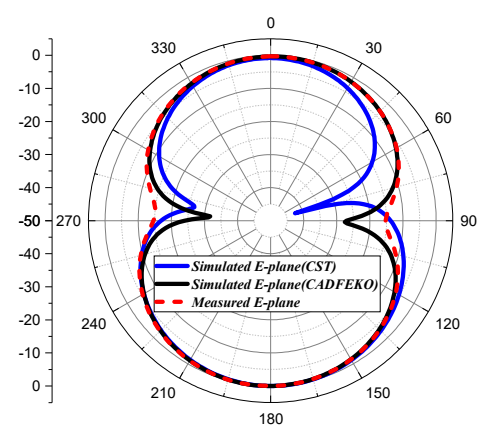

(a)

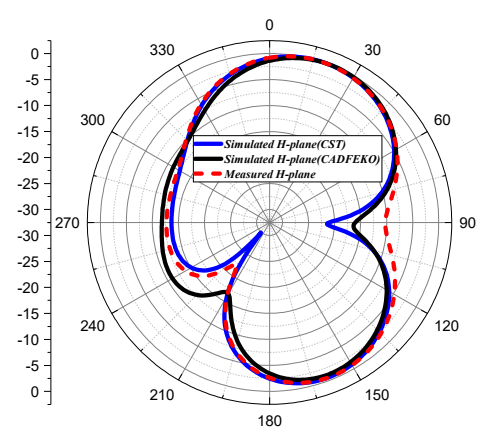

(c)

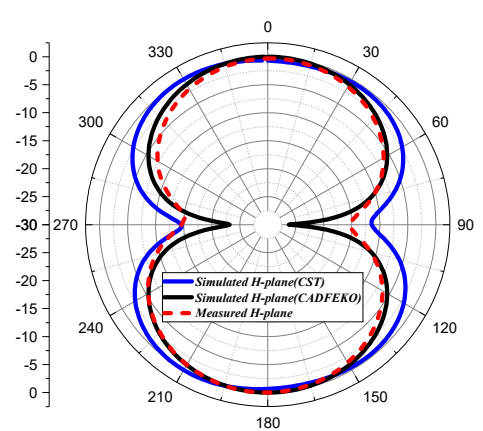

(b)

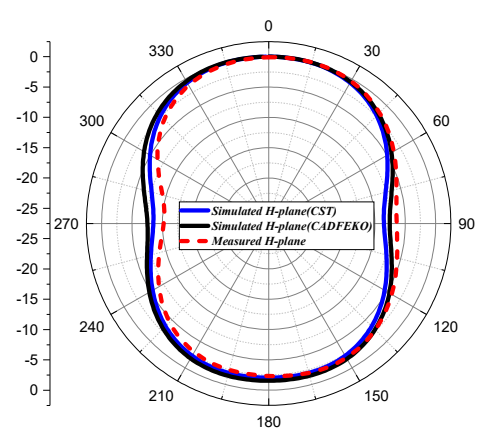

(d)

Figure 13. Two-dimensional radiation patterns: (a) E-plane at $3.6 \mathrm{GHz}$, (b) $\mathrm{H}$-plane at $3.6 \mathrm{GHz}$, (c) E-plane at $5.3 \mathrm{GHz}$, (d) H-plane at $5.3 \mathrm{GHz}$. 


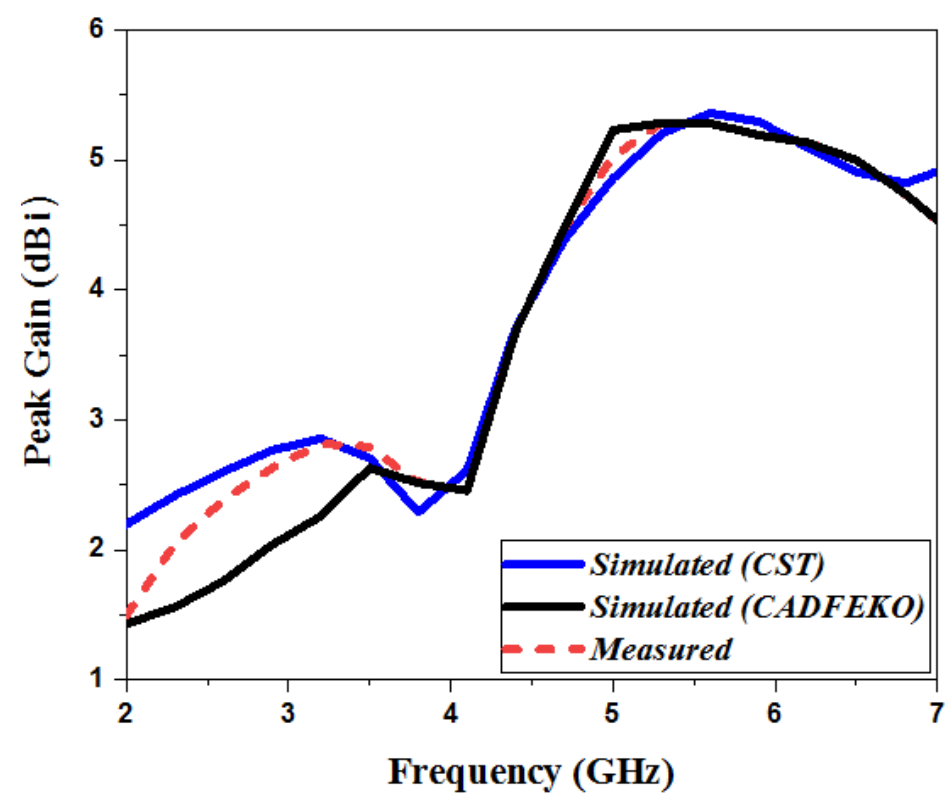

Figure 14. Simulated and measured peak gain of the suggested antenna versus frequency.

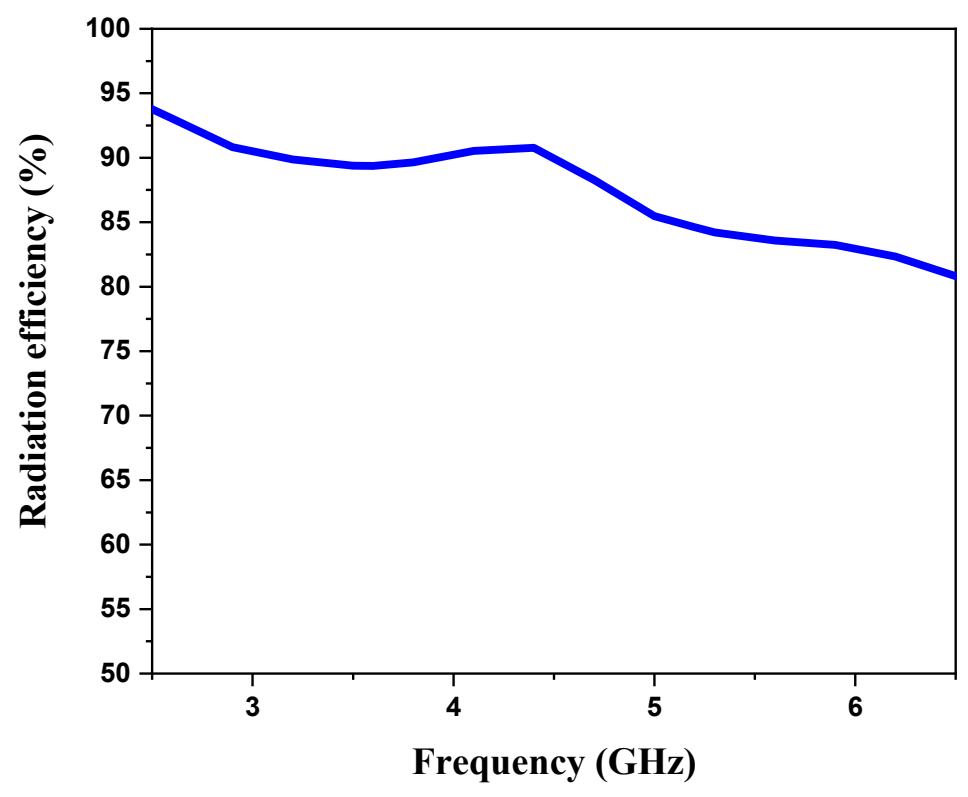

Figure 15. Simulated radiation efficiency of the suggested antenna.

The simulation results obtained by the CADFEKO and CST solvers, as well as the measurement results, are collected and summarized in Table 2. The impedance bandwidth is $4.15 \mathrm{GHz}$ with two operating frequencies 3.5 and $5.1 \mathrm{GHz}$ for CADFEKO, and the impedance bandwidth is about $4.35 \mathrm{GHz}$ with two resonant frequencies at 3.6 and $5.2 \mathrm{GHz}$ for CST. The measured impedance bandwidth is $4.22 \mathrm{GHz}$, with two operating frequencies at 3.6 and $5.3 \mathrm{GHz}$. In addition, when evaluating gain values, the CST result is 2.75 and $5.37 \mathrm{dBi}$ at 3.6 and $5.2 \mathrm{GHz}$, respectively. In addition, the CADFEKO result is 2.63 and $5.26 \mathrm{dBi}$ at 3.5 and $5.1 \mathrm{GHz}$, respectively, and the measured gain value was around 2.78 and $5.32 \mathrm{dBi}$ at 3.6 and $5.3 \mathrm{GHz}$. As a result, for the impedance bandwidth, resonant frequencies and gain comparison, the CST produced results that were closer to the measured results. The CST based on the FIT approach produced a better outcome for broadband antennas, as predicted by the literature [25]. 
Table 2. Summary of simulation and measurement results of the suggested antenna.

\begin{tabular}{ccccccc}
\hline $\begin{array}{c}\text { Antenna } \\
\text { Performance }\end{array}$ & \multicolumn{2}{c}{ Simulated (CADFEKO) } & \multicolumn{2}{c}{ Simulated (CST) } & \multicolumn{2}{c}{ Measured } \\
\hline$f_{r}(\mathrm{GHz})$ & 3.5 & 5.1 & 3.6 & 5.2 & 3.6 & 5.3 \\
\hline$S_{11}(\mathrm{~dB})$ & -23.3 & -23.9 & -42.7 & -50.06 & -41.3 & -57.2 \\
\hline Gain $(\mathrm{dBi})$ & 2.63 & 5.26 & 2.7 & 5.36 & 2.78 & 5.32 \\
\hline Bandwidth $(\mathrm{GHz})$ & & 4.15 & \multicolumn{2}{c}{4.35} & \multicolumn{2}{c}{4.22} \\
\hline
\end{tabular}

Table 3 compares the proposed broadband antenna for WLAN and WIMAX applications to various antennas previously reported in the literature. The antenna presented in $[17,22]$ did not shift all the resonant frequencies of WLAN and WiMAX applications and had a large size. The antenna proposed in [18] provided a low gain compared to our designed antenna. In ref. [19], the antenna had a large size and narrow impedance bandwidth. In ref. [20], the antenna had a simple structure; moreover, it did not cover all the required bands of WLAN and WiMAX and it provided a lower gain compared to our antenna. In ref. [21], the antenna had a complex structure printed in Taconic RF-35, it achieved a broadband, and it did not cover all the bands of WLAN and WiMAX. The suggested broadband antenna has various advantages over previously reported antennas [8-22] in terms of size, impedance bandwidth and gain, as shown by the comparison.

Table 3. Comparison of the suggested antenna performances with other antennas in the literature.

\begin{tabular}{|c|c|c|c|c|c|c|}
\hline Ref No. & Size $\left(\mathrm{mm}^{2}\right)$ & $\begin{array}{l}\text { Type of } \\
\text { Substrate }\end{array}$ & $\begin{array}{c}\text { Frequency } \\
\text { Range (GHz) }\end{array}$ & $\begin{array}{l}\text { Bandwidth } \\
\text { (GHz) }\end{array}$ & $\begin{array}{c}\text { Resonant } \\
\text { Frequency (GHz) }\end{array}$ & $\begin{array}{l}\text { Peak Gain } \\
\quad \text { (dBi) }\end{array}$ \\
\hline [17] & $60 \times 90$ & FR-4 & $\begin{array}{l}2.3-3 \\
4.7-6\end{array}$ & $0.7,1.3$ & $2.4,5.2,5.6$ & $4.76,2.9,2.44$ \\
\hline [18] & $57 \times 31.2$ & FR-4 & $\begin{array}{c}2.3-2.6 \\
2.9-3.8 \\
4.8-5.65\end{array}$ & $0.3,0.9,0.85$ & $2.45,3.5,5.5$ & $1.19,1.59,2.39$ \\
\hline [19] & $56 \times 37$ & FR-4 & $\begin{array}{c}2.24-2.5 \\
3.6-3.99 \\
4.4-4.6 \\
5.71-5.9\end{array}$ & $\begin{array}{c}0.26,0.39,0.2 \\
0.19\end{array}$ & $2.43,3.83,4.48,5.8$ & $2.2,2.8,3.3,4.2$ \\
\hline [20] & $60 \times 60$ & FR-4 & $\begin{array}{l}2.3-2.6 \\
3.3-3.7 \\
\end{array}$ & $0.3,0.4$ & $2.46,3.5$ & $2.61,2.7$ \\
\hline [21] & $120 \times 70$ & Taconic RF-35 & $2.2-4.18$ & 1.98 & $2.46,3.5$ & $4.11,6.48$ \\
\hline [22] & $60 \times 45$ & FR-4 & $\begin{array}{l}2.25-2.95 \\
3.35-3.61\end{array}$ & $0.7,0.26$ & $2.6,3.5$ & $7.1,7.3$ \\
\hline This work & $50 \times 50$ & FR-4 & $2.48-6.7$ & 4.22 & $3.6,5.3$ & $2.78,5.32$ \\
\hline
\end{tabular}

\section{Conclusions}

A novel broadband octagonal microstrip patch antenna with Vicsek fractal slots suitable for WLAN and WiMAX applications is proposed. This antenna is printed in FR-4 substrate with dimensions of $50 \times 50 \times 1.6 \mathrm{~mm}^{3}$. The measurement results confirm that this antenna has a broadband 2.48 to $6.7 \mathrm{GHz}$ and two resonant frequencies of 3.6 and $5.3 \mathrm{GHz}$, respectively, which cover the WiMAX bands $(2.3 / 2.5 / 3.3 / 3.5 / 5 / 5.5 \mathrm{GHz})$ and WLAN bands (2.4-2.5/3.6/4.9-5.9 GHz). This antenna achieves considerable peak gains, 2.78 and $5.32 \mathrm{dBi}$, and radiation efficiencies 88.5 and $84.6 \%$ at the resonant frequencies. Moreover, the proposed antenna offers an omnidirectional radiation pattern in the H-plane and in the E-plane. 
Author Contributions: Conceptualization, O.B., S.A., M.S., K.C., A.R., A.G., S.K., M.A. and E.L.; data curation, O.B., S.A., M.S., K.C., A.R. and A.G.; formal analysis, O.B., S.A., M.S., K.C., A.R., A.G. and M.A.; funding acquisition, M.A. and E.L.; investigation, O.B., S.A., M.S., K.C., A.R., A.G., S.K., M.A. and E.L.; methodology, O.B., S.A., M.S., K.C., A.R., A.G., S.K., M.A. and E.L.; project administration, O.B., S.A., A.G., M.A. and E.L.; resources, O.B., S.A., M.S., A.R., A.G., S.K., M.A. and E.L.; software, O.B., S.A., K.C., A.R. and A.G.; supervision, A.G., M.A. and E.L.; validation, O.B., S.A., M.S., K.C., A.R., A.G., S.K., M.A. and E.L.; visualization, O.B., S.A., M.S., K.C., A.R., A.G., S.K., M.A. and E.L.; writing-original draft, O.B., S.A., A.G.; writing-review and editing, O.B., S.A., M.S., K.C., A.R., A.G., S.K., M.A. and E.L. All authors have read and agreed to the published version of the manuscript.

Funding: This project has received funding from Universidad Carlos III de Madrid and the European Union's Horizon 2020 research and innovation program under the Marie Sklodowska-Curie Grant 801538. Also, the work was partially supported by the Researchers Supporting Project number (RSP-2021/58), King Saud University, Riyadh, Saudi Arabia.

Institutional Review Board Statement: Not applicable.

Informed Consent Statement: Not applicable.

Data Availability Statement: All data are included within the manuscript.

Acknowledgments: The authors appreciate the funding from Universidad Carlos III de Madrid and the European Union's Horizon 2020 research and innovation program under the Marie SklodowskaCurie Grant 801538. In addition the partial support from the Researchers Supporting Project number (RSP-2021/58), King Saud University, Riyadh, Saudi Arabia, is acknowledged.

Conflicts of Interest: The authors declare no conflict of interest.

\section{References}

1. Prashanth, K.V.; Umamaheswari, B.; Akhil, G.; Krishna, G.V.; Chandu, M.V.S. A Compact Antenna with WiMAX and WLAN bands notched for UWB applications. IJET 2018, 7, 489. [CrossRef]

2. Chandan. Truncated Ground Plane Multiband Monopole Antenna for WLAN and WiMAX Applications. IETE J. Res. 2020, 1-6. [CrossRef]

3. Geetharamani, G.; Aathmanesan, T. A Metamaterial Inspired Tapered Patch Antenna for WLAN/WiMAX Applications. Wirel. Pers. Commun. 2020, 113, 1331-1343. [CrossRef]

4. Al-Gburi, A.J.A.; Ibrahim, I.B.M.; Zeain, M.Y.; Zakaria, Z. Compact Size and High Gain of CPW-Fed UWB Strawberry Artistic Shaped Printed Monopole Antennas Using FSS Single Layer Reflector. IEEE Access 2020, 8, 92697-92707. [CrossRef]

5. Benkhadda, O.; Saih, M.; Chaji, K.; Reha, A. Design and Analysis of Rectangular Microstrip Patch Antenna using Different Feeding Mechanisms for $2.45 \mathrm{GHz}$ Applications. JARDCS 2020, 12, 1205-1217. [CrossRef]

6. Liu, G.; Liu, Y.; Gong, S. Compact tri-band wide-slot monopole antenna with dual-ring resonator for WLAN/WiMAX applications. Microw. Opt. Technol. Lett. 2016, 58, 1097-1101. [CrossRef]

7. Reha, A.; El Amri, A. Design, Realization and Measurements of CPW-Fed Miscrostrip Hexagonal Patch Antenna with H-Tree Fractal Slots for WLAN and WIMAX Applications. IJMOT 2016, 11, 251-258.

8. Tarbouch, M.; El Amri, A.; Terchoune, H.; Barrou, O. Compact CPW-Fed Microstrip Octagonal Patch Antenna with Hilbert Fractal Slots for WLAN and WIMAX Applications. In Innovations in Smart Cities and Applications; Ahmed, M.B., Boudhir, A.A., Eds.; Springer International Publishing: Cham, Germany, 2018; Volume 37, pp. 432-444. [CrossRef]

9. Reha, A.; El Amri, A.; Benhmammouch, O.; Said, A.O.; El Ouadih, A.; Bouchouirbat, M. CPW-fed slotted CANTOR Set fractal antenna for WiMAX and WLAN applications. Int. J. Microw. Wirel. Technol. 2017, 9, 851-857. [CrossRef]

10. Rahman, M.; NagshvarianJahromi, M.; Mirjavadi, S.; Hamouda, A. Compact UWB Band-Notched Antenna with Integrated Bluetooth for Personal Wireless Communication and UWB Applications. Electronics 2019, 8, 158. [CrossRef]

11. Li, L.; Zhang, X.; Yin, X.; Zhou, L. A Compact Triple-Band Printed Monopole Antenna for WLAN/WiMAX Applications. Antennas Wirel. Propag. Lett. 2016, 15, 1853-1855. [CrossRef]

12. Ibrahim, A.; Fazil, N.A.; Dewan, R. Triple-band antenna with defected ground structure (DGS) for WLAN/WiMAX applications. J. Phys. Conf. Ser. 2020, 1432, 012071. [CrossRef]

13. Brar, R.S.; Saurav, K.; Sarkar, D.; Srivastava, K.V. A quad-band dual-polarized monopole antenna for GNSS/UMTS/WLAN/WiMAX applications. Microw. Opt. Technol. Lett. 2018, 60, 538-545. [CrossRef]

14. Naik, K.K. Asymmetric CPW-fed SRR patch antenna for WLAN/WiMAX applications. AEU Int. J. Electron. Commun. 2018, 93, 103-108. [CrossRef]

15. Kumar, D.N. Asymmetric CPW Fed Miniaturized dual polarized monopole Antenna for WLAN/WiMAX Applications. J. Phys. Conf. Ser. 2020, 1451, 012017. [CrossRef]

16. Yeboah-Akowuah, B.; Tchao, E.T.; Ur-Rehman, M.; Khan, M.M.; Ahmad, S. Study of a printed split-ring monopole for dualspectrum communications. Heliyon 2021, 7, e07928. [CrossRef] 
17. Palandoken, M. Dual broadband antenna with compact double ring radiators for IEEE $802.11 \mathrm{ac} / \mathrm{b} / \mathrm{g} / \mathrm{n}$ WLAN communication applications. Turk. J. Electr. Eng. Comput. Sci. 2017, 25, 1325-1333. [CrossRef]

18. Chu, H.B.; Shirai, H. A compact metamaterial quad-band antenna based on asymmetric E-CRLH unit cells. PIER C 2018, 81, 171-179. [CrossRef]

19. Chouhan, S.; Panda, D.K.; Kushwah, V.S.; Singhal, S. Spider-shaped fractal MIMO antenna for WLAN/WiMAX/Wi$\mathrm{Fi} /$ Bluetooth/C-band applications. AEU Int. J. Electron. Commun. 2019, 110, 152871. [CrossRef]

20. Ali, W.A.E.; Ashraf, M.I.; Salamin, M.A. A dual-mode double-sided $4 \times 4$ MIMO slot antenna with distinct isolation for WLAN/WiMAX applications. Microsyst. Technol. 2021, 27, 967-983. [CrossRef]

21. Altaf, A.; Seo, M. Dual-Band Circularly Polarized Dielectric Resonator Antenna for WLAN and WiMAX Applications. Sensors 2020, 20, 1137. [CrossRef]

22. Liu, S.; Wu, W.; Fang, D.-G. Single-Feed Dual-Layer Dual-Band E-Shaped and U-Slot Patch Antenna for Wireless Communication Application. Antennas Wirel. Propag. Lett. 2016, 15, 468-471. [CrossRef]

23. Balanis, C.A. Antenna Theory: Analysis and Design, 3rd ed.; John Wiley: Hoboken, NJ, USA, 2005.

24. Abdulbari, A.A.; Jawad, M.M.; Hanoosh, H.O.; Saare, M.A.; Lashari, S.A.; Sari, S.A.; Ahmad, A.; Khalill, Y.; Hussain, Y.M. Design compact microstrip patch antenna with T-shaped 5G application. Bull. Electr. Eng. Inform. 2021, 10, 2072-2078. [CrossRef]

25. Bilgin, G.; Yilmaz, V.S.; Kara, A.; Aydin, E. Comparative assessment of electromagnetic simulation tools for use in microstrip antenna design: Experimental demonstrations. Microw. Opt. Technol. Lett. 2019, 61, 349-356. [CrossRef] 